\title{
Proceeding
}

10th INSHS International Christmas Sport Scientific Conference, 4-5 December 2015. International Network of Sport and Health

Science. Szombathely, Hungary

\section{Women football spectatorship in the Czech Republic}

\author{
PETR SCHOLZ
}

Faculty of Sports Studies, Masaryk University, Brno, Czech Republic

\begin{abstract}
Football is a phenomenon of the last decades and also due to fans it could become the most popular sport in the world throughout its history. Football is bringing happiness, fulfilment and thrill to billion people all over the world. But on the other hand it is also riven with corruption, racism, homophobia and violence. The goal of this paper is to analyze the relationship between fans' verbal and other expression and their violent behavior at Eden football stadium in the Czech Republic. A pilot study was performed in 2015 year, with data collected from women fans $(n=77)$ aged $22.9 \pm 6.4$ years old. All of the respondents were attending in a stand of home team supporters. This paper uses quantitative research, methods of analysis, mathematical and statistical methods. In our pilot study, we found that physical aggression against rival fans in the stadium is considered the most serious expression of violent behavior by $73 \%$ of the respondents. Furthermore, $62 \%$ of the respondents found the most serious activity firing of pyrotechnics. Physical aggression against police and riot police marked $57 \%$ of the respondents for the most serious expression. $55 \%$ of the respondents signified the most serious activity demolishing stadium. Triggers for their behavior are mostly alcohol or other addictive substance or referee's mistake. Only $35 \%$ of the respondents did not meet with the destruction of the stadium and other riots. Also, based on the results of the pilot study, we find that classic fans under 23 years of age are more tolerant of negative social phenomena in the surroundings of the stadium. Key words: AGGRESSION, BEHAVIOR, FANS, VIOLENCE.
\end{abstract}

Corresponding author. Division of History, Philosophy, Sociology and Psychology of Sport. Faculty of Sports Studies, Masaryk University, Kamenice 5, 62500 Brno, Czech Republic

E-mail: petr.scholz@mail.muni.cz

10th INSHS International Christmas Sport Scientific Conference, 4-5 December 2015. International Network of Sport and Health Science. Szombathely, Hungary.

JOURNAL OF HUMAN SPORT \& EXERCISE ISSN 1988-5202

(c) Faculty of Education. University of Alicante

doi:10.14198/jhse.2016.11.Proc1.02 


\section{INTRODUCTION}

Sport in the form of active sport as a passive spectator consumption is one of the most important social phenomena that extends to politics, economy, but also affects the arts and education. We can say that it is one of the most important means of mass entertainment worldwide and leisure fills a large part of the population regardless of national borders or socio-cultural formation (Slepička et al., 2010). Sports spectatorship is currently considered an important social phenomenon that is linked to other areas of human activity. Football spectatorship is an integral part of sport spectatorship, and thanks to the frequency of audience and phenomena associated with football spectatorship is thus the subject of numerous sociological, psychological, socio-psychological and demographic researches. Given the long history of spectator sports events consumption it is not surprising fact that there were also serious manifestations of spectator aggression. From medieval times, games featuring balls or animal (and maybe human) skulls were played on holy days only or as part of festivals; these were wild, unruly affairs, with not so many rules and little structure for better understanding. They were also extremely violent, games often resulting in deaths and serious injuries or wounds (Cashmore \& Cleland, 2014).

Coakley (1998) defines aggression as behavior that intends to destroy property or injure another person. It is also grounded in a total disregard for the well-being of self and others. The spectators' aggression is displayed in various forms. There are a lot of different scientific studies about explanation of aggressive behavior. The best known study is by Wann \& Branscombe (1993). They used the self-esteem maintenance model which describes the strong commitment that fans have with their football team. When the team wins, the fans are inclined to have higher self-esteem and their social identity is enhanced. This is more characteristic for the fans that have stronger relations with their team. The spectators that have low identification with the team, simply need to cut themselves off from the team if the team is not successful, thus maintaining a positive self-image. This is very difficult thing to do for sport spectators that have a high level of identification with their team. Self-esteem tends to decrease with the team's failures, which can lead spectators or fans to the derogation processes. This is their attempt to restore the damage done to their selfesteem (Slepička \& Slepičková 2007; Slepička et al., 2012).

Football is undoubtedly the most popular sport in the world, and subsequently an important aspect of popular culture. The need for professional, clubs to operate as more of a business entity has never been greater. But football has a dark side (Williams, 2013; Cashmore \& Cleland, 2014). Frosdick \& Marsh (2005) state that football fan behavior has been for many years a major cause for concern throughout Europe, especially in Germany, Netherlands, Italy and Belgium, as well as in the United Kingdom. Substantial disturbances at football matches have also been witnessed in the Czech Republic, Greece, Denmark, Austria and other countries in Eastern Europe. Veuthey \& Freeburn (2015) point to the fact that although the term hooliganism refers to acts of violence or disturbances that might occur among sports spectators, the term is most often associated with football environment. Frosdick \& Marsh (2005) said that violent and anti-social behavior amongst football fans is sometimes referred to as the British disease or English disease. These populist terms have been used by the media and by politicians to label deviant behaviors. But these labels are based on three popular mistakes: that the violence is something relatively new; that it is found at football matches only; and that it is an English phenomenon. None of these statements stands up to scrutiny. In recent years, the issue of football hooliganism has become the subject of intense media, political and academic interest.

Czech football has no history of widespread of serious violence, but there have been some reports of incidents during the 1980s and early 1990s, mainly involving Sparta Prague fans. Incidents have occurred within the stadium and involved attacks on opposing players, although fans of Sparta Prague have also 
caused damage to trains towards to away-matches and been involved in street fighting after matches with Slavia Prague (Duke, 1990). In the new millennium there were interrupted several matches due to the ravages of hooligans in the auditorium f. e. between Baník Ostrava and Sparta Prague (2014); fight fans at the derby between Slavia Prague and Sparta Prague (2008) with police and riot police. Nevertheless, the matches were played without any termination as they had been planned. Conversely, in the semifinals of the domestic cup between Slavia Prague and Sigma Olomouc (2011), Slavia fans penetrated during the half time break on the grass. They were subsequently adjusted by riot police, the match was interrupted and the game won due to the forfeit of the opponent. In the former UEFA Cup (now European league), hooligans caused considerable damage at the stadium and in the city center during the match between Sparta Prague and Spartak Moscow (2007). Furthermore, in revenge match of the European League between Slovan Bratislava and Sparta Prague (2014) game was interrupted several times due to riots hooligans in the stands. Unfortunately, oftentimes ignorance and misunderstanding of football hooliganism determines preview on it. It is important to distinguish hooligans from other people who are interested only in football and watch football matches (table 1).

Table 1. Distinction between spectators, fans, and hooligans

\begin{tabular}{llll}
\hline Criterion & Spectators & Fans & Hooligans \\
\hline Stability of group & low & high & high \\
Integration of group & low & high & high \\
Cohesion & low & medium & high \\
Attractiveness of group & low & high & high \\
Stability of group & low & medium & high \\
Autonomy of group & low & medium & high \\
Size of group & large & medium & small \\
Degree of intimacy in group & low & medium & high \\
Accessibility of group & high & medium & low \\
Homogeneity/heterogeneity & heterogeneous & homogeneous & homogeneous \\
Focus of group & low & medium & high \\
Focus on values & low & medium & high \\
Degree of satisfaction & low & medium & high \\
Degree of attractiveness & low & medium & high \\
Degree of control & low & medium & high \\
Violent behavior & low & medium & high \\
Displays of nationalism & low & high & high \\
Expressions of xenophobia and racism & non-existent & infrequent & frequent \\
Degree of ideological focus & non-existent & non-existent & high \\
Judgment of game & objective & subjective & subjective \\
Club chauvinism & low & high & low \\
\hline
\end{tabular}

Source: processed under Mareš et al., 2004.

In this context, it is possible to identify three major groups: football spectators, football fans and football hooligans (table 1; Mareš et al., 2004). But the most used division is the division according to Smolík (2008) that divides the various audiences at football stadiums into four groups: inactive spectators, classical fans, hooligans and ultras.

\section{MATERIAL AND METHODS}

The goal of this paper is to analyze the relationship between fans' verbal and other expression and their violent behavior at Eden football stadium in the Czech Republic. Following the goal we set a research question: Which speeches are considered by football fans at Eden football stadium the most serious? 
Primary data were collected by a questionnaire survey at the Eden stadium in 2015 . The pilot study is focused on the oldest football clubs in the Czech Republic, so we chose Slavia Prague and their fans. A total of 77 women respondents aged $22.9 \pm 6.4$ years old years old participated in this pilot study. All of the respondents were attending in a stand of home team supporters. The next reason for choosing this football club was finding that this section of the stadium (behind the goal) is the most occupied by football fans and spectators. The questionnaire consisted of twenty nine questions; some of them were scalable, where respondents rated on Likert scale individual verbal and other expression and also their violent behavior speeches from the least serious to the most serious. This paper uses quantitative research, methods of analysis, mathematical and statistical methods.

\section{RESULTS}

Almost $1 / 5$ of the respondents (19 \%) own a season ticket of their favorite club for home matches. Also, $82 \%$ of the respondents prefer supporting their club in a group, $8 \%$ of the respondents favor individual chanting, and $10 \%$ of the respondents do not support anymore, they are interested in a football match only and they visit this sector for active fans due to the cheapest ticket for a game. Respondents evaluated the speeches which can be found at the football stadiums in the Czech Republic. The evaluation was using a Likert scale (1-10) and speech that appeared to be the least serious, was rated 1, the most significant speech received the highest grade, i.e. 10.

The firing of pyrotechnics evaluated more than a half of the respondents (62 \%) as very serious activity, on the other hand, more than $1 / 4$ of the respondents $(30 \%)$ even identified this activity as less serious activity. Regarding vulgar chanting of the stand or vulgar individual expression, we recorded a corresponding response. $30 \%$ of the respondents said that vulgar individual expression is not a serious problem. Physical aggression against rival fans at the stadium found nearly $3 / 4$ of the respondents (73\%) as the most serious activity, and other respondents (23\%) called it as a very significant problem. Only $4 \%$ of the respondents considered this activity for the least serious. Similar results (57\% and $24 \%$ ) were noted in the physical aggression against the police or riot police. Only $4 \%$ of the respondents said that physical aggression against the police is not a serious problem.

Arranged hooligan fight outside the stadium evaluated almost $1 / 2$ of the respondents (42\%) as the most serious activity, another $23 \%$ of the respondents identified this activity as a major problem. More than $1 / 5$ of the respondents $(21 \%)$ believe that throwing objects onto the pitch is also the most significant activity, as confirmed by $35 \%$ of the respondents, who called it serious activity, too. The most frequently situations are during the wrong verdict of side referee or the opposing players celebrate a goal in front of the home stand and the football pitch is often sprinkled with empty or full cups of beer, pennies or even lighters. We can conclude that referees' negotiations in some cases can even become igniter of violent clashes, even when referees are acting contrary to the rules of football. In the better case it is perceived as improper behavior by sports fans in the stand, or in the worst case directly as a provocation.

Demolished stadium and other riots in it identified more than one half of the respondents ( $55 \%$ ) as the most serious activity, a further $23 \%$ of the respondents said that it is very serious activity. However, there are some individuals $(4 \%)$ who believe that the demolition of the stadium is not a serious problem. We expected that the percentage of the respondents will be higher (grade 10), especially for sports fans, who mostly supported their football club. Almost a half of the respondents (43\%) rated racism with the highest grade; other respondents did not found these statements against dark-skinned players as a major problem. Whistling at the football stadiums does not consider any of the respondents as the most important activity 
that should disappear from the stadiums. In contrast, almost one half of the respondents ( $38 \%$ ) believed that it is a minimal problem, and a further $40 \%$ of the respondents are confident about it, too. Penetration on the pitch is considered by $9 \%$ of the respondents as the most important activity; on the other hand, almost one half of the respondents ( $45 \%$ ) said that it is not a significant problem (table 2).

Table 2. Activities during the football matches in percentage

\begin{tabular}{lccccccccccc}
\hline activities during the football matches & 1 & 2 & 3 & 4 & 5 & 6 & 7 & 8 & 9 & 10 & $\Sigma$ \\
\hline firing of pyrotechnics & 0 & 0 & 16 & 14 & 4 & 0 & 0 & 0 & 4 & $\mathbf{6 2}$ & 100 \\
vulgar chants in the stand & 14 & 4 & 16 & 4 & 19 & 0 & 0 & $\mathbf{2 7}$ & 16 & 0 & 100 \\
individual vulgar expression & $\mathbf{3 0}$ & 0 & 4 & 8 & 16 & 0 & 4 & 19 & 19 & 0 & 100 \\
physical aggression against rival fans at the stadium & 0 & 0 & 4 & 0 & 0 & 0 & 0 & 15 & 8 & $7 \mathbf{3}$ & 100 \\
physical aggression against police and riot police & 0 & 0 & 0 & 4 & 0 & 15 & 0 & 16 & 8 & $\mathbf{5 7}$ & 100 \\
arranged hooligan fight outside the stadium & 0 & 0 & 0 & 0 & 0 & 19 & 16 & 4 & 19 & $\mathbf{4 2}$ & 100 \\
throw in the subject on the pitch & 0 & 4 & 0 & 0 & 4 & 0 & 19 & 17 & $\mathbf{3 5}$ & 21 & 100 \\
demolishing stadium and other riots & 0 & 0 & 4 & 0 & 0 & 14 & 4 & 0 & 23 & $\mathbf{5 5}$ & 100 \\
expressions of racism & 0 & 0 & 0 & 0 & 37 & 4 & 16 & 0 & 0 & $\mathbf{4 3}$ & 100 \\
whistles & $\mathbf{3 8}$ & 8 & 16 & 16 & 19 & 3 & 0 & 0 & 0 & 0 & 100 \\
penetration on the pitch & 0 & 23 & $\mathbf{4 5}$ & 0 & 4 & 8 & 0 & 4 & 7 & 9 & 100 \\
\hline
\end{tabular}

Source: Own elaboration, 2015.

Approximately the same results we noticed in the use of pyrotechnics. Nearly $1 / 5$ of the respondents (16\%) met with pyrotechnics in the majority of matches, and $15 \%$ of the respondents meet with firing of pyrotechnics every game. Only $8 \%$ of the respondents met with vulgar chants in the stand in the majority of matches, with individual vulgar expressions there is almost one half of the respondents $(47 \%)$. This number is several times higher if we compare these mentioned expressions. With physical aggression against rival fans at the stadium had never more than $1 / 2$ of the respondents $(51 \%)$ and more than $1 / 5$ of the respondents $(22 \%)$ clashed with it in less than a half of the matches. Physical aggression against police and riot police achieved similar results, $26 \%$ of the respondents had encountered with it in less than a half of the matches, and $51 \%$ of the respondents did not meet with it anymore.

More than $1 / 3$ of the respondents (38\%) have never met with an appointed hooligan fight. It is alarming but the value that $39 \%$ of the respondents met with this conflict, even if it is less than one half of the matches. Also throwing objects onto the pitch saw almost $2 / 3$ of the respondents $(62 \%)$, similar results we noticed with demolishing stadium and other riots $(53 \%)$. These two mentioned activities happen in less than one half of the matches. Nearly $1 / 3$ of the respondents $(31 \%)$ reported that they did not meet with racism, on the other hand $53 \%$ of the respondents met with these abusive expressions in less than one half of the matches). Almost $3 / 4$ of the respondents ( $73 \%$ ) experienced with whistles at the stadium every match, further $12 \%$ of the respondents met with whistles on the majority of the matches. Nearly one half of the respondents (49\%) did not meet with penetration on the pitch (table 3). 
Table 3. Frequency of the activities during the matches in percentage

\begin{tabular}{lcccccc} 
activities during the football matches & $\begin{array}{c}\text { every } \\
\text { football } \\
\text { match }\end{array}$ & $\begin{array}{c}\text { majority } \\
\text { of the } \\
\text { matches }\end{array}$ & $\begin{array}{c}1 / 2 \\
\text { matches }\end{array}$ & $\begin{array}{c}\text { less than } \\
1 / 2 \\
\text { matches }\end{array}$ & never & $\Sigma$ \\
\hline firing of pyrotechnics & 15 & 16 & 22 & $\mathbf{4 3}$ & 4 & 100 \\
vulgar chants in the stand & 30 & 8 & $\mathbf{3 9}$ & 8 & 15 & 100 \\
individual vulgar expression & 18 & $\mathbf{4 7}$ & 4 & 16 & 15 & 100 \\
physical aggression against rival fans at the stadium & 0 & 8 & 19 & 22 & $\mathbf{5 1}$ & 100 \\
physical aggression against police and riot police & 0 & 4 & 19 & 26 & $\mathbf{5 1}$ & 100 \\
arranged hooligan fight outside the stadium & 4 & 0 & 19 & 39 & $\mathbf{3 8}$ & 100 \\
throw in the subject on the pitch & 4 & 0 & 30 & $\mathbf{6 2}$ & 4 & 100 \\
demolishing stadium and other riots & 0 & 4 & 8 & $\mathbf{5 3}$ & 35 & 100 \\
expressions of racism & 0 & 4 & 12 & $\mathbf{5 3}$ & 31 & 100 \\
whistles & $\mathbf{7 3}$ & 11 & 0 & 16 & 0 & 100 \\
penetration on the pitch & 0 & 0 & 27 & 24 & $\mathbf{4 9}$ & 100 \\
\hline
\end{tabular}

Source: Own elaboration, 2015.

\section{DISCUSSION}

Football clubs and organizers look at the classical fan and football supporter primarily as an economic factor. It is important to remember that they are also responsible for work with football fans. It is evident that the media play a very significant role in the public's view of football hooliganism. In our opinion football clubs and media should focus on educational broadcasting, promoting fair play and critically evaluating acts of violence.

The goal of this paper is to analyze the relationship between fans' verbal and other expression and their violent behavior at Eden football stadium in the Czech Republic. Following the goal we set a research question: Which speeches are considered by football fans at Eden football stadium the most serious?

In our pilot study, we found that the most serious speech is physical aggression against rival fans in the stadium, which confirmed $73 \%$ of the respondents. Furthermore, $62 \%$ of the respondents found the most serious activity firing of pyrotechnics. Physical aggression against police and riot police marked $57 \%$ of the respondents for the most serious expression. $55 \%$ of the respondents signified the most serious activity demolishing stadium. Triggers for their behavior are mostly alcohol or other addictive substance or referee's mistake. Only more than a third of the respondents $(35 \%)$ did not meet with the destruction of the stadium and other riots. Also, based on the results of the pilot study, we find that classical fans under 23 years old are more tolerant of negative social phenomena in the surroundings of the stadium, which confirms Slepička et al. (2010), who conducted research on the number of 5,629 spectators.

\section{CONCLUSIONS}

In order to encounter for increasingly less socially negative phenomena in the stands and around the stadiums it is more than desirable to utilize all existing preventive measures sufficiently. Anti-hooligan laws and regulations have been adopted and implemented in the United Kingdom in the 80s of the 20th century. Nowadays, these means have proven to be as the best to combat violence at football stadiums and served as a model and guide for other European countries struggling with similar problems. The English system against hooliganism is the result of a long process and it is relatively comprehensive, both on public and private levels. 
Currently, the stadiums in the Czech Republic only sell non-alcoholic beer during derby or other risky matches (f. e. Baník Ostrava), there are separate sectors or stands for fans who want to support their team. The sale of tickets for risky matches is possible with identity card only and personal inspection is more thorough, etc. The Football Association of the Czech Republic considers the addressable ticketing and CCTV systems in the future.

We consider the social prevention to be the most important factor to avoid the football acts of violence. With this help it is possible to capture new incoming fans and hooligans. The intention is to direct these individuals to positively support football players and teams, i.e. without violence, individual and group vulgarities, racist insults etc.

\section{REFERENCES}

1. Cashmore, E., \& Cleland, J. (2014). Football's Dark Side. Corruption, Homophobia, Violence and Racism in the Beautiful Game. Basingstoke: Palgrave Macmillan.

2. Coakley, J. J. (1998). Sport in scoiety: Issues and controversies. Irwin/McGraw-Hill.

3. Duke, V. (1990). Perestroika in progress? The case of spectator sports in Czechoslovakia. Brit J. Sociol., 41(2), 145-156.

4. Frosick, S., \& Marsh, P. (2005). Football Hooliganism. Willan Publishing.

5. Mareš, M. et al. (2004). Fotbaloví chuligáni: evropská dimenze subkultury. Brno: Centrum strategických studií a Barrister \& Pricipal.

6. Slepička, P. et al. (2010). Divácká reflexe sportu. Univerzita Karlova: Karolinum.

7. Slepička, P. et al. (2012). Psychosociální aspekty agrese ve sportu. Czech Kinanthropology, Prague, 16(2), 1-21.

8. Slepička, P., \& Slepičková, I. (2007). Problems of sport spectators in sport psychology. Acta Universitatis Carolinae, Kinanthropologica, 43(1), 57-68.

9. Smolík, J. (2008). Fotbalové chuligánství. Historie, teorie a politizace fenoménu. Karlovy Vary: Zdeněk Plachý.

10. Wann, D. L., \& Branscombe, N. R. (1993). Sport Fans: Measuring Degree of Identification with Their Team. Int. J. Sport Psychol., 24(1), 1-17.

11. Veuthey, A., \& Freeburn, L. (2015). The Fight Against Hooliganism in England: Insights for Other Jurisdictions? Melb. J. Int'l L, 16(1), 203-255.

12. Williams, A. M. (2013). Science and Soccer. Developing Elite Performers. New York: Routledge. 